\title{
The residual monomer content and mechanical properties of CAD $\backslash C A M$ resins used in the fabrication of complete dentures as compared to heat cured resins
}

\author{
Al-Dharrab Ayman
}

Ph.D., Associate Professor \& Consultant in Department of Oral and Maxillofacial Prosthodontics, Faculty of Dentistry, King Abdulaziz University, Jeddah, Saudi Arabia

\section{Type of article: Original}

\begin{abstract}
Background: The utilization of computer-assisted designing and computer-assisted milling CAD $\backslash C A M$ resins in the fabrication of removable prostheses is a modern-day concept that offers many advantages over the use of the traditional polymethylmethacrylate (PMMA).

Aim: This study instigated some of the mechanical properties of CAD $\backslash C A M$ denture base resin including the amount of residual monomer.

Methods: This study was conducted at the Faculty of Dentistry, King Abdulaziz University from October 2016 to February 2017. A total of seventy rectangular specimens were fabricated (group A: 35 heat-cured PMMA and group B: $35 \mathrm{CAD} / \mathrm{CAM}$ pre-polymerized acrylic resin blocks). The flexural strength and surface hardness were tested while the residual monomer content at baseline, two-day and seven-day intervals was estimated using gas chromatography (GC). Means and standard deviations were determined for each group as well as independentsamples t-test and ANOVA with repeated measures for comparison between the groups and subgroups of varying time intervals.

Results: Heat cured PMMA (A), displayed higher flexural strength and low value flexural modulus compared to $\mathrm{CAD} / \mathrm{CAM}$ acrylic resin denture base material (B). Student t-test indicated highly significant differences $(\mathrm{p}<0.001)$ of the flexural strength $(\mathrm{t}=37.911)$ and flexural modulus $(\mathrm{t}=88.559)$. The surface hardness of group (B) was significantly higher compared to group (A) as indicated by the $t$-test $(t=20.430)$. Higher release of the monomer content was detected by GC in group (A) at different time intervals with a statistically significant difference $(\mathrm{p}<0.001)$ in residual monomer content.

Conclusion: CAD/CAM resin may be considered suitable for use in the construction of denture bases.

Keywords: Acrylic resin, Dentures, Residual monomer, Flexural strength, Surface hardness
\end{abstract}

\section{Introduction}

Heat cured polymethylmethacrylate (PMMA) resin is the most widely used material for the construction of removable prostheses (1) due to its superior physical and chemical characteristics, ease of processing and reasonable cost. However there are a few limiting properties, most importantly is the release of residual methyl methacrylate monomer (MMA) which affects the dimensional stability, the adherence of oral bacteria such as Candida albicans to the resin and the prolonged chair side appointments required for the fabrication of the prostheses (2). Such limitations have led general practitioners to shy away from treating edentulous patients (3-5). The presence of residual monomer in denture base resins adversely affects both the mechanical properties and the biocompatibility of these resins as leaching out of the monomer gives rise to allergic reactions with symptoms such as burning sensations, stomatitis, oedema and ulceration of the oral mucosa (6). The employment of computer-assisted designing and computer-assisted milling (CAD $\backslash C A M)$ technology in the fabrication of removable prostheses may eliminate such disadvantages (7). The application of CAD $\backslash$ CAM technology is increasing in dental laboratories and

\section{Corresponding author:}

Associate Professor Dr. Al-Dharrab Ayman, Department of Oral and Maxillofacial Prosthodontics, Faculty of Dentistry, King Abdulaziz University, PO. Box: 80209, Jeddah 21589, Saudi Arabia.

Tel.: +966 2 6403316. Email: aaldharab@kau.edu.sa

Received: March 26, 2017, Accepted: April 27, 2017, Published: July 2017

iThenticate screening: April 27, 2017, English editing: May 12, 2017, Quality control: May 15, 2017

(C) 2017 The Authors. This is an open access article under the terms of the Creative Commons Attribution-NonCommercialNoDerivs License, which permits use and distribution in any medium, provided the original work is properly cited, the use is non-commercial and no modifications or adaptations are made. 
clinical practices alike $(8,9)$. CAD $\backslash C A M$ systems offer numerous clinical benefits since the PMMA pucks used for the milling of denture are polymerised under high temperature and pressure, a process that promotes the formation of longer polymer chains leading to a higher degree of monomer conversion and lower values of residual monomer as well as minimal porosity (10-16). The level of residual MMA in denture base resins has been investigated through various methods such as infrared spectroscopy (IR), high performance liquid chromatography (HPLC) and gas chromatography (GC) (17-19). However, some limitations are inherent to some tests. For example, Infrared spectrophotometry suffers from the overlapping of absorption peaks in the complex spectra and ample preparation for HPLC analysis is complex. On the other hand, GC is a convenient test as it separates the monomer without decomposition, requires short run times and offers a high sensitivity range (20). This study aimed to evaluate some of the flexural strength and hardness properties of CAD $\backslash$ CAM denture base resin and to determine the amount of residual monomer content in these resins using the gas chromatography analytical technique GC.

\section{Material and Methods}

\subsection{Study design}

This study was carried out from October 2016 to February 2017 at the Faculty of Dentistry, King Abdulaziz University (Saudi Arabia). Resin specimens measuring $65 \mathrm{~mm}$ in length, $10 \mathrm{~mm}$ in width and $3 \mathrm{~mm}$ in thickness were fabricated and consisted of two types: group A (heat cured PMMA) and group B (CAD $\backslash$ CAM pre-polymerized acrylic resin). Group A: The lost wax technique was employed to construct the moulds that were then packed using heat-cured acrylic resin (Vertex RS. Dentimex, Netherlands) according to the manufacturer's instructions then processed in a metal flask. These specimens were processed for 9 hours in a water bath, and kept at a constant temperature of $165^{\circ} \mathrm{F}\left(73.5^{\circ} \mathrm{C}\right)$. Conventional cutters and trimmers were used for finishing and polishing. Group B: The CAD/CAM pre-polymerized acrylic resin blocks (Polident d.o.o. Volčja Draga 42, S1-5293 Volčja Draga, Slovenia) were cut with an Isomet saw (Isomet, Buehler, USA) under running water then ground on 800-grit SIC. All specimens were stored in distilled water at $37^{\circ} \mathrm{C}$ for 24 hours.

\subsection{Mechanical and chemical testing}

Specimens were divided into three subgroups: Subgroup 1: Flexural strength and flexural modulus test (10 specimens); Subgroup 2: Surface Hardness test (10 specimens); Subgroup 3: Gas chromatography GC analysis (15 specimens).

\subsection{Flexural strength test}

Flexural strength testing was conducted using the Instron testing machine (Instron 5944, 2kn. 825 University Ave, Norwood, MA, USA). This was through applying the three-point testing design with a centrally loaded specimen beam at a cross-head speed of five $\mathrm{mm} / \mathrm{min}$ over a two-point support span that was set at thirty $\mathrm{mm}$. The force required for break samples was recorded using the universal testing machine software (Bluehill3, V3.12, Illinois Tool Works Inc. USA). The flexural strength was calculated applying the following equation (1):

$\mathrm{S}=3 . \mathrm{P} \cdot \mathrm{L} / 2 \cdot \mathrm{b} \cdot \mathrm{d}^{2}$

Where:

$\mathrm{S}$ : flexural strength (MPa)

$\mathrm{P}$ : maximum load applied $(\mathrm{N})$

L: support span length ( $\mathrm{mm})$

b: width $(\mathrm{mm})$

d: thickness (mm)

The flexural modulus (E) was computed using the equation (2):

$\mathrm{E}=\mathrm{FL}^{3} / 4 \mathrm{ybd}^{3}$

Where:

F: load applied

Y: deflection

L: support span length (mm)

b: width (mm)

d: thickness (mm)

\subsection{Surface Hardness Test}

Surface hardness was determined by means of a digital Micromet hardness tester (Micromet 6040, Buehler LTD, Illinois 60044. USA) with load of 50 gf for 10 seconds (dwell time) applied using a blunt pointed indenter. 
Measurements were obtained and calculated using the built-in software (Buehler OmniMet MHT 7.3, Buehler LTD, Illinois 60044. USA). Five areas per sample were tested and the mean value of these readings was measured to determine hardness.

\subsection{Gas chromatography (GC)}

Gas chromatography was used to measure the residual monomer content in all specimens immediately following processing (subgroup a), at 2 days and 7 days of storing in distilled water (subgroup b and c respectively). The solvents of analytical reagent grade (Merck, Frankfurter Str. 250, 64293 Darmstadt, Germany) were used. A solution of hydroquinone (HQ), methanol and acetone was prepared with a concentration of $20 \mathrm{ppm}$ as a stabilizer of MMA. Internal standard (I.S.) solution was prepared using $750 \mathrm{mg}$ butanol and methanol to a total volume of $25 \mathrm{ml}$. The concentration of the prepared I.S. in the solution was approximately $(30 \mathrm{mg} / \mathrm{ml})$. Working standard solution consisted of $142 \mathrm{mg}$ of MMA and methanol with a concentration of $(14.2 \mathrm{mg} / \mathrm{ml}) .100 \mu \mathrm{l}$ of working standard solution, $200 \mu \mathrm{l}$ of the internal standard solution were added to $10 \mathrm{ml}$ methanolic solution to give a final concentration of $0.142 \mathrm{mg} / \mathrm{ml}$.
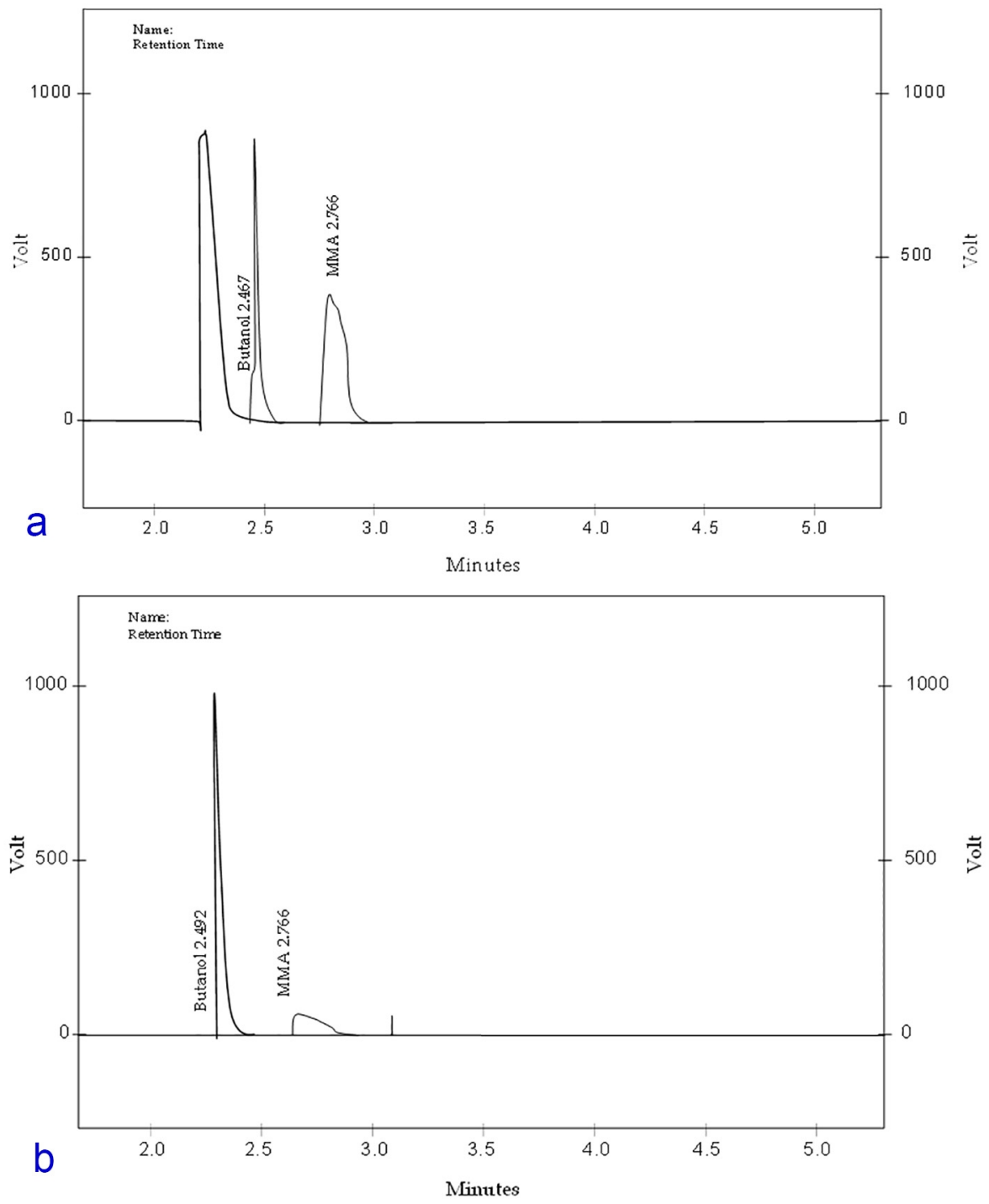

Figure 1. Peak of butanol (internal standard) and retention time of MMA by gas chromatography of group (A) and group (B) 


\subsection{GC sample preparation}

six hundred fifty $\mathrm{mg}$ of resin (groups A and B) were placed into the acetone diluting solution and stirred with stirring bars for 72 hours at room temperature to create slurry. Two $\mathrm{ml}$ of this slurry was added to the final methanol diluted solution and five $\mathrm{ml}$ of this mixture slurry was transferred by pipette to a glass centrifugation tube. The slurry was centrifuged (3000 rpm for $15 \mathrm{~min}$ ) then one $\mu \mathrm{l}$ was tested using the GC (Shimadzu, Chiyoda-ku, Tokyo 101, Japan). This system utilized a gas chromatograph with a flame ionization detector (FID) on a fused-silica capillary column RTX-5 $(30 \mathrm{~m} \times 0.23 \mathrm{~mm}$ i.d. $0.25 \mu \mathrm{m}$ ft.) with $5 \%$ phenylmethylpolysiloxane coating and split mode (10:1) injection at $200{ }^{\circ} \mathrm{C}$, the column temperature. The temperature was raised from $40{ }^{\circ} \mathrm{C}$ to $100{ }^{\circ} \mathrm{C}$ at a rate of $20^{\circ} \mathrm{C} / \mathrm{min}$. The carrier gas (N2) was set at a flow rate of $1.2 \mathrm{ml} / \mathrm{min}$ and detection at $250{ }^{\circ} \mathrm{C}$ with a ratio of H2/air at $45 / 450$. The standard sample peak retention time and area were compared to the test sample to calculate the concentration (Figure 1). The content of residual monomer was determined via standard calibration curve. The monomer content in the sample solution and in the test specimens (groups A and B and their subgroups) was calculated (3).

\subsection{Statistical analysis}

In this comparative study, means and standard deviations were determined for each group as well as independentsamples t- test and ANOVA with repeated measures for comparison between the groups and subgroups of varying time intervals.

\section{Results}

The mean distribution and standard deviation values of flexural strength, flexural modulus and surface hardness are presented in (Table 1). The mean value of flexural strength in group (A) was $62.38 \pm 1.73 \mathrm{MPa}$, which was significantly higher than that of group (B) $34.05 \pm 2.32 \mathrm{MPa}$ as indicated by $\mathrm{t}$-test $(\mathrm{t}=37.911)(\mathrm{p}<0.001)$. Student $\mathrm{t}$-test also calculated the mean value of flexural modulus at $5 \%$ level of group (A) to be significantly lower than group (B) $(\mathrm{t}=88.559)(\mathrm{p}<0.001)$. Results are displayed in Figure 2. The surface hardness of group (B) revealed a considerably higher mean value at $22.41 \pm 1.50$ compared to group (A) at $13.22 \pm 0.88$, with a statistical significant difference at $5 \%$ level among the two groups according to the $\mathrm{t}$-test $(\mathrm{t}=20.430)(\mathrm{p}<0.001)$. Results are displayed in Figure 3 . Table 2 presents the GC results of the mean residual monomer content released at different time intervals in all samples (groups A, B and their subgroups). The mean value of residual monomer content in group (A) was higher than those of group (B). ANOVA, with repeated measures was used for comparison within the subgroups at different time intervals and revealed a statistically significant difference $(F=174.194$ and 492.759$)(p<0.001)$. The student $t$-test displayed a high statistically significant difference $(\mathrm{p}<0.001)$ at $5 \%$ level as shown in Table 2 .

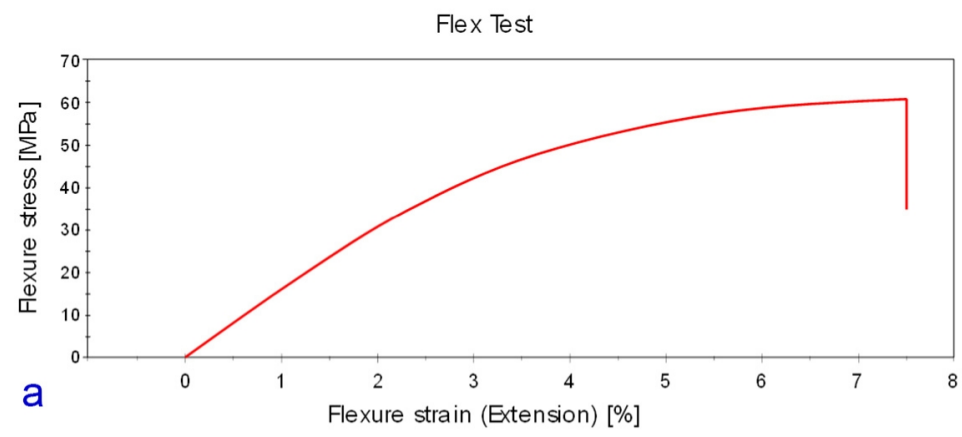

Fex Test

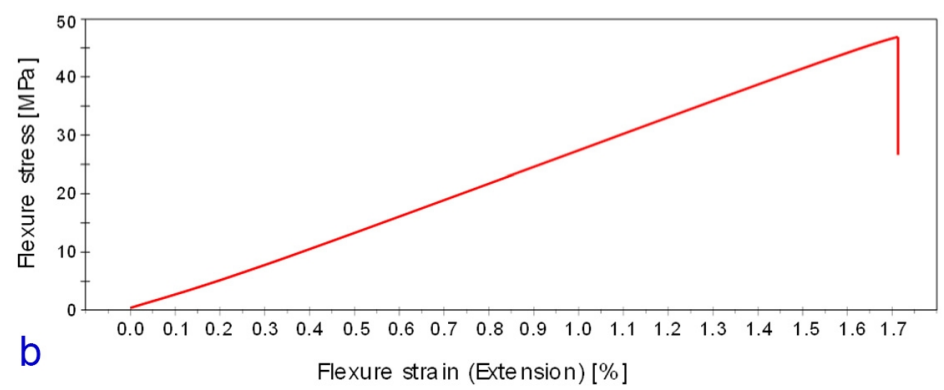

Figure 2. Flexure strength of group (A) and group (B). 

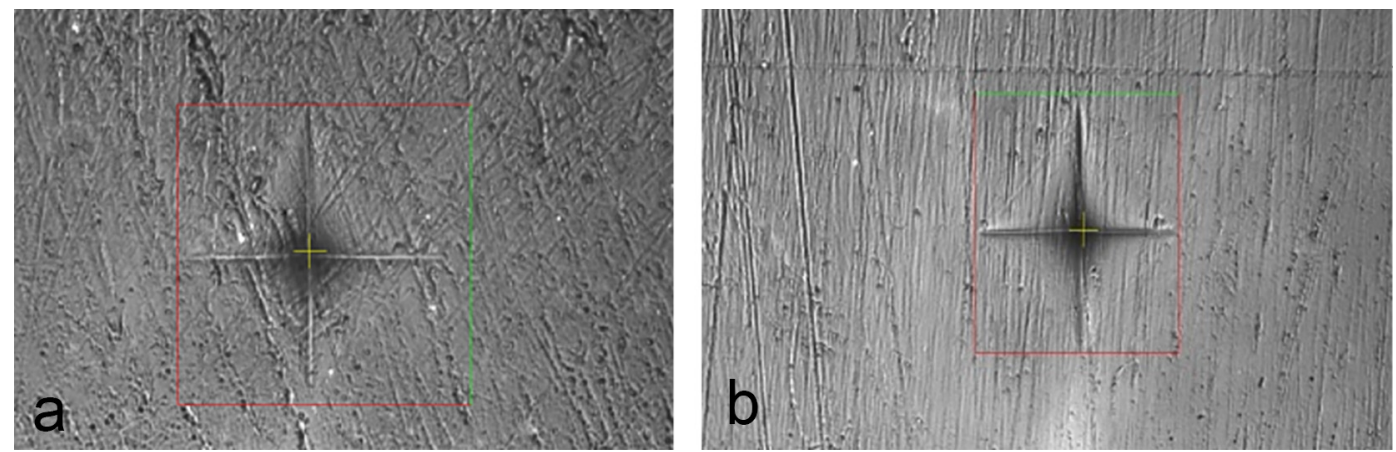

Figure 3. Surface hardness of group (A) and group (B).

Table 1. Mean value, standard deviation and t-test for flexural strength, flexural modulus and surface hardness of heat cured and $\mathrm{CAD} / \mathrm{CAM}$ acrylic resin denture bases

\begin{tabular}{|c|c|c|c|}
\hline Resin & $\begin{array}{l}\text { Flexural strength } \\
\text { Mean } \pm \text { SD }(\mathrm{MPa})\end{array}$ & $\begin{array}{l}\text { flexural modulus } \\
\text { Mean } \pm \text { SD (MPa) }\end{array}$ & $\begin{array}{l}\text { Surface Hardness } \\
\text { Mean } \pm \text { SD (MPa) }\end{array}$ \\
\hline Heat Cure PMMA & $62.38 \pm 1.73$ & $1.55 \pm 0.06$ & $13.22 \pm 0.88$ \\
\hline CAD/CAM resin & $34.05 \pm$ & $2.85 \pm 0.01$ & $22.41 \pm 1.50$ \\
\hline $\mathrm{t}$ - test & $37.911^{*}$ & $88.559^{*}$ & $20.430^{*}$ \\
\hline$p$-value & $<0.001^{*}$ & $<0.001^{*}$ & $<0.001^{*}$ \\
\hline
\end{tabular}

$*$ Statistically significant at $\mathrm{p} \leq 0.05$

Table 2. The mean value, standard deviation of residual monomer content of group A and group B in gas chromatography at different time intervals, $t$ and $\mathrm{p}$ values for Student $\mathrm{t}$-test for comparing between the two groups. F test (ANOVA) with repeated measures for comparison between different periods.

\begin{tabular}{|l|l|l|l|l|l|}
\hline \multirow{2}{*}{ Resin } & \multicolumn{3}{|l|}{ Gas chromatography } & F & p-value \\
\cline { 2 - 7 } & Baseline & 2 Days & 7 Days & & \\
\hline Heat Cure PMMA & $17.10 \pm 0.38$ & $16.04 \pm 0.13$ & $13.54 \pm 0.46$ & $174.194^{*}$ & $<0.001^{*}$ \\
\hline CAD/CAM resin & $1.61 \pm 0.05$ & $1.03 \pm 0.06$ & $0.90 \pm 0.01$ & $492.759^{*}$ & $<0.001^{*}$ \\
\hline $\mathrm{t}$ & $90.261^{*}$ & $235.221^{*}$ & $61.934^{*}$ & & \\
\hline p-value & $<0.001^{*}$ & $<0.001^{*}$ & $<0.001^{*}$ & & \\
\hline
\end{tabular}

*Statistically significant at $\mathrm{p} \leq 0.05$

\section{Discussion}

CAD/CAM technology has multiple prosthetic applications including the fabrication of intra-coronal and extracoronal restorations, crowns, fixed partial dentures and more recently, the construction of complete denture and maxillofacial prostheses (21). CAD/CAM allows the use of novel materials with improved characteristics (9) but it is crucial to understand and assess the mechanical properties of these newer materials. CAD/CAM denture base acrylic resin is supplied as pre-polymerized blocks which are produced in industrially controlled conditions with standardized pressure and temperature parameters. These blocks, which are easily milled, have gained popularity in recent years in the fabrication of removable prostheses. It is crucial to examine the mechanical properties such as flexural strength, flexural modulus and surface hardness as these replicate the clinical loading patterns applied to a denture intra orally. This is an important factor to consider as patients use their removable prostheses for extended periods of time $(8,22-24)$. In the current investigation, the heat cure acrylic denture base of group (A) showed a higher flexural strength with low flexural modulus compared to the tested CAD/CAM acrylic resin denture base material of group (B) despite the similarity in the PMMA composition of both resins. These findings could be due to the higher release of the monomer content, which was detected by GC in group (A), that adversely affects the mechanical properties as a result of plasticizing the polymeric chain, resulting in greater resin deformation under loading (20). The decrease of flexural strength with increase flexural modulus of group (B) is probably a result of the processing method under high temperature - pressure leading to a low residual MMA concentration. It has been reported that these processing conditions decrease the intermolecular distances and reduce the free volume (25). Surface hardness indicates the density of the material and its resistance to wear and/or scratching which reflects on the dental prosthesis during its function and cleaning (14). The results of the present study showed a significant difference in surface hardness of the $\mathrm{CAD} / \mathrm{CAM}$ resin compared to heat cured PMMA resin. These may be 
attributed to the polymerization process of each resin as the heat cure is polymerized by additional (free radical) polymerization and leads to the formation of a partial cross-linked polymer chain which results in the superior hardness. On the other hand, the high temperature and high-pressure conditions for the polymerization of $\mathrm{CAD} / \mathrm{CAM}$ resins and the addition of inorganic fillers restrict dimensional polymerization shrinkage and enhance the $\mathrm{CAD} / \mathrm{CAM}$ resins mechanical properties including hardness and wear resistance (24-26). Such properties also decrease surface deterioration and the adhesion of bacterial plaque $(14,27)$. High monomer content has detrimental effects on the mechanical properties of the resin, reduces the glass transition temperature which renders the resin softer and more flexible and adversely affects the prostheses clinical performance. Determining the content of residual monomer in denture base resin using gas chromatography is a simple and rapid yet reliable technique.

\section{Conclusions}

Gas chromatography analysis of residual MMA in polymerized denture base material offers sufficient accuracy to measure the residual monomer in acrylic denture base materials with minimal sample preparation. The findings of the current study indicate a reduction of monomer content in CAD/CAM resin which could be attributed to the method of polymerization under high pressure. $\mathrm{CAD} / \mathrm{CAM}$ acrylic resin denture base is considered as a clinically suitable resin for the construction of denture bases. Further investigation of the mechanical properties of CAD/CAM materials are necessary to assess other aspects prior to clinical trials.

\section{Acknowledgments:}

The author acknowledges with thanks for the use of the facilities of The Advanced Technology Dental Research Laboratory, Faculty of Dentistry, King Abdulaziz University, for technical support.

\section{Conflict of Interest:}

There is no conflict of interest to be declared.

\section{References:}

1) Ucar Y, Akova T, Aysan I. Mechanical properties of polyamide versus different PMMA denture base materials. J Prosthodont. 2012; 21(3): 173-6. doi: 10.1111/j.1532-849X.2011.00804.x. PMID: 22372855.

2) Awad AK, Jassim RK. The effect of plasma on transverse strength, surface roughness and Candida adhesion of two types of acrylic denture base materials (Heat cure and light cure). J Bagh Coll Dentistry. 2012; 24: 10-17. doi: 10.0001/1350.

3) Baba NZ. Materials and Processes for CAD/CAM Complete Denture Fabrication. Curr Oral Health Rep. 2016; 3(3): 203-8. doi: 10.1007/s40496-016-0101-3.

4) Berdicevsky I, Ben-Aryeh H, Szargel R, Gutman D. Oral candida of asymptomatic denture wearers. Int J Oral Surg. 1980; 9(2): 113-5. doi: 10.1016/S0300-9785(80)80047-0. PMID: 6773894.

5) Budtz-Jörgensen E. The significance of Candida albicans in denture stomatitis. Scand J Dent Res. 1974; 82(2): 151-90. PMID: 4598186.

6) Lee HJ, Kim CW, Kim YS. The level of residual monomer in injection molded denture base materials. J Korean Acad Prosth. 2003; 41(3): 360-8.

7) Steinmassl PA, Wiedemair V, Huck C, Klaunzer F, Steinmassl O, Grunert I. Do CAD/CAM dentures really release less monomer than conventional dentures? Clin Oral Investig. 2016; 21(5): 1697-1705. doi: 10.1007/s00784-016-1961-6. PMID: 27704295.

8) Digholkar S, Madhav VN, Palaskar J. Evaluation of the flexural strength and microhardness of provisional crown and bridge materials fabricated by different methods. J Indian Prosthodont Soc. 2016; 16(4): 328-34. doi: 10.4103/0972-4052.191288. PMID: 27746595, PMCID: PMC5062140.

9) van Noort R. The future of dental devices is digital. Dent Mater. 2012; 28(1): 3-12. doi: 10.1016/j.dental.2011.10.014. PMID: 22119539.

10) Kattadiyil MT, Goodacre CJ, Baba NZ. CAD/CAM complete dentures: a review of two commercial fabrication systems. J Calif Dent Assoc. 2013; 41(6): 407-16. PMID: 23875432.

11) Bidra AS, Taylor TD, Agar JR. Computer-aided technology for fabricating complete dentures: systematic review of historical background, current status, and future perspectives. J Prosthet Dent. 2013; 109(6): 361 6. doi: 10.1016/S0022-3913(13)60318-2. PMID: 23763779.

12) Kattadiyil MT, Jekki R, Goodacre CJ, Baba NZ. Comparison of treatment outcomes in digital and conventional complete removable dental prosthesis fabrications in a predoctoral setting. J Prosthet Dent. 2015; 114(6): 818-25. doi: 10.1016/j.prosdent.2015.08.001. PMID: 26412000. 
13) Nguyen JF, Ruse D, Phan AC, Sadoun MJ. High-temperature-pressure polymerized resin-infiltrated ceramic networks. J Dent Res. 2014; 93(1): 62-7. doi: 10.1177/0022034513511972. PMID: 24186559, PMCID: PMC3872849.

14) Murakami N, Wakabayashi N, Matsushima R, Kishida A, Igarashi Y. Effect of high-pressure polymerization on mechanical properties of PMMA denture base resin. J Mech Behav Biomed Mater. 2013; 20: 98-104. doi: 10.1016/j.jmbbm.2012.12.011. PMID: 23455166.

15) Akin H, Tugut F, Polat ZA. In Vitro comparison of the cytotoxicity and water sorption of two different denture base systems. J Prosthodont. 2015; 24(2): 152-5. doi: 10.1111/jopr.12162. PMID: 24920440.

16) Lamb DJ, Ellis B, Priestley D. The effects of process variables on levels of residual monomer in autopolymerizing dental acrylic resin. J Dent. 1983; 11(1): 80-8. doi: 10.1016/0300-5712(83)90051-9. PMID: 6573363.

17) Urban VM, Cass QB, Oliveira RV, Giampaolo ET, Machado AL. Development and application of methods for determination of residual monomer in dental acrylic resins using high performance liquid chromatography. Biomed Chromatogr. 2006; 20(4): 369-76. doi: 10.1002/bmc.575. PMID: 16177959.

18) Jassim RK, Radhi AAA. Evaluation amount of residual monomer in two types of denture base materials Heat and Light cure acrylic reinforced with Silainated glass Fiber. Iraqi Dent J. 2015; 37(1).

19) Sadamori S, Kotani H, Hamada T. The usage period of dentures and their residual monomer contents. J Prosthet Dent. 1992; 68(2): 374-6. doi: 10.1016/0022-3913(92)90349-F. PMID: 1501194.

20) Lung CY, Darvell BW. Methyl methacrylate in poly(methyl methacrylate)--validation of direct injection gas chromatography. J Chromatogr A. 2004; 1061(1): 93-8. doi: 10.1016/j.chroma.2004.10.088. PMID: 15633748.

21) Albero A, Pascual A, Camps I, Grau-Benitez M. Comparative characterization of a novel cad-cam polymer-infiltrated-ceramic-network. J Clin Exp Dent. 2015; 7(4): e495-500. doi: 10.4317/jced.52521. PMID: 26535096, PMCID: PMC4628804.

22) Gurbuz O, Unalan F, Dikbas I. Comparison of the Transverse Strength of Six Acrylic Denture Resins. OHDMBSC. 2010; IX(1): 21-4.

23) Powers JM, Sakaguchi RL. Craig'S Restorative Dental materials. 12th ed. Elsevier, Mosby; 2006.

24) Consani RLX, Pucciarelli MGR, Mesquita MF, Nogueira MC, Barao VA. Polymerisation cycles on hardness and surface gloss of denture base. Int J Contemp Dent Med Rev. 2014; 2014: 1-6. doi: 10.15713/ins.ijcdmr.8.

25) Ali IL, Yunus N, Abu-Hassan MI. Hardness, flexural strength, and flexural modulus comparisons of three differently cured denture base systems. J Prosthodont. 2008; 17(7): 545-9. doi: 10.1111/j.1532849X.2008.00357.x. PMID: 18761582.

26) Nakayama M, Takagi N. Methods for manufacturing dental resin block. US; 2016.

27) Douglas WH, Bates JF. The determination of residual monomer in polymethylmethacrylate denture base resins. J material science. 1978; 13(12): 2600-4. doi: 10.1007/BF02402746. 